2019

\title{
Effectiveness of Surf Therapy for Children With Disabilities
}

\author{
Emily D. Clapham \\ Linda S. Lamont \\ Minsuk Shim \\ Shabnam Lateef \\ Cortney N. Armitano \\ Old Dominion University, carmitan@odu.edu
}

Follow this and additional works at: https://digitalcommons.odu.edu/hms_fac_pubs

Part of the Movement and Mind-Body Therapies Commons, and the Physical Therapy Commons

\section{Repository Citation}

Clapham, Emily D.; Lamont, Linda S.; Shim, Minsuk; Lateef, Shabnam; and Armitano, Cortney N., "Effectiveness of Surf Therapy for Children With Disabilities" (2019). Human Movement Sciences Faculty Publications. 94.

https://digitalcommons.odu.edu/hms_fac_pubs/94

\section{Original Publication Citation}

Clapham, E. D., Lamont, L. S., Shim, M., Lateef, S., \& Armitano, C. N. (2019). Effectiveness of surf therapy for children with disabilities. Disability and Health Journal, 1-6. doi:10.1016/j.dhjo.2019.100828

This Article is brought to you for free and open access by the Human Movement Sciences at ODU Digital Commons. It has been accepted for inclusion in Human Movement Sciences Faculty Publications by an authorized administrator of ODU Digital Commons. For more information, please contact digitalcommons@odu.edu. 


\section{Effectiveness of Surf Therapy for Children with Disabilities}

Manuscript word count: 3,628

Number of references: 37

Number of figures/tables: 4

Key Words: Surf Therapy; Children with Disabilities; Adapted Physical Education

Emily D. Clapham, Ed.D. is an associate professor in the Department of Kinesiology, the University of Rhode Island, Kingston, Rhode Island 02881.

Phone: (401) 874-5447

Linda S. Lamont, Ph.D. is a Professor of Kinesiology in the Department of Kinesiology at the University of Rhode Island, Kingston, Rhode Island 02881.

Minsuk Shim, Ph.D. is an Associate Professor of Education in the School of Education at the University of Rhode Island, Kingston, Rhode Island 02881.

Shabnam Lateef, M.S. is a lecturer in the Department of Kinesiology at the University of Rhode Island, Kingston, Rhode Island 02881.

Cortney N. Armitano, M.S. is a doctoral student in the Department of Human Movement Science at Old Dominion University, Norfolk, Virginia 23510.

Grant Funding: Grant funding to support the program was obtained from the John Fogarty Foundation, Doug Flutie Foundation, Bailey's Team Foundation, and from the Brayden Carr Foundation and a local surf shop, Peter Pan Surf Academy, donated 50\% of the cost of the equipment rentals.

The manuscript has not been published and will not be submitted elsewhere for publication while being considered by the journal Disability Health Journal. The manuscript has been accepted for presentation at the International Symposium on Adapted Physical Activity (ISAPA 2019). We suspect an abstract may be published for this conference.

As the corresponding author, I certify that all funding information and conflict-of-interest disclosures are complete for both myself and my co-authors, to the best of my knowledge. Funding information and conflict-of-interest disclosures appear on the title page and, if the manuscript is accepted, will be published. 


\begin{abstract}
Background: Few researchers have examined the effects of surf programs on children with disabilities. Due to previous research findings, surfing is being used, as the focus of physical activity intervention due to its numerous health and therapeutic benefits.

Objective/Hypothesis: The purpose of this study was to explore the effects of an eight-week surfing intervention on various physical fitness measures in 71 children with disabilities such as autism spectrum disorder, down syndrome, global developmental delays, and cerebral palsy. The study also sought to compare the differences in overall fitness levels between the surf therapy group and an unstructured pool playgroup. Researchers predicted significant differences in the surf therapy group.
\end{abstract}

Methods: The assessment procedure consisted of pre and post physical fitness measures selected from the Brockport Physical Fitness Test in two groups: surfing $(n=71)$ and an unstructured aquatic program $(n=20)$.

Results: The results demonstrated significant improvements in core strength $(p=0.00)$, upper body strength $(p=0.00)$, flexibility $(p=0.01)$ and cardiorespiratory endurance $(p=0.00)$ in the surfing group. However, there were no significant differences in overall fitness levels between the surfing and unstructured pool playgroups. Body composition measurements on the surfing group demonstrated a significant reduction in total body fat $\%(p=0.016)$ and fat free mass $(p=$ $0.008)$ and a significant improvement in bone mineral density $(\mathrm{p}=0.004)$ pre to post surf therapy. 
Conclusions: This research demonstrated the effectiveness and physiological benefits of surf therapy for children with selected disabilities.

Key words: surf therapy, children with disabilities, adapted physical education 
Effectiveness of Surf Therapy for Children with Disabilities

\section{Introduction}

Obesity is a public health concern ${ }^{1}$. The prevalence of obesity among U.S. youth aged 2-19 years is $17 \%$ and therefore affects about 12.7 million youth and adolescents ${ }^{2}$. To lower the risk for this and other diseases, it is recommended that children, ages 6-17, accumulate 60 minutes or more of aerobic, muscle strengthening, and bone strengthening physical activity each day, and complete each type of physical activity three times a week ${ }^{3}$. Participation in sports and recreational activities also provide opportunities for these children that promote inclusion, minimize deconditioning, optimize physical functioning, and enhance overall well being4. Unfortunately, children with sensory, intellectual and physical disabilities are three times more likely to have lower fitness levels and greater obesity than their typically developing peers ${ }^{5,6}$. This limited childhood participation puts them at greater risk for secondary health problems ${ }^{7,8,9}$ in adulthood such as: dyslipidemia, coronary artery disease, osteoporosis, and diabetes. Not only are opportunities to participate in fitness programs limited for children with disabilities; so is leisure, recreational and competitive sport pursuits ${ }^{4,10,11}$.

The sport of surfing has recently been introduced into the Olympics, and it is now a part of the physical education curriculum in California ${ }^{12}$ and Hawaii ${ }^{13}$. It became an official school sport in Hawaii in $2013^{13}$. Globally there are several surf programs offered to people with disabilities and our research team and others have examined the benefits of surfing for children with disabilities ${ }^{14,15,16,17,18,19}$. In addition, there are reports of social benefits. Surfing significantly altered an exercise-induced affect, with significant improvements reported for positive affect and tranquility, and significant reductions in negative affect and fatigue in a single 30-minute surfing bout $^{20}$. 
Results revealed surfers paddle $44 \%$ of the total time ${ }^{21}$, followed by stationary periods $(42 \%)^{21}$. Heart rate (HR) measurements during surfing practice have been reported to average between $75 \%$ and $85 \%$ of the mean HR values measured during a laboratory based incremental arm paddling test in which peak $\mathrm{VO} 2$ was measured ${ }^{22}$. Measurements of surfing duration, average, and maximum HR were made on high school PE students over an 8-week period using heart rate monitors ${ }^{12}$ (Polar FTI). The average duration that these PE students participated in surfing during class was $61.7 \pm 1.0$ minutes. Stationary, paddling, wave riding, and miscellaneous activities comprised $42.7 \pm 9.5,36.7 \pm 7.9,2.9 \pm 1.4$, and $17.8 \pm 11.4$ percent of the surf session, respectively. The average and maximum HRs during these activities were 131.1 $\pm 0.9 \mathrm{~b} \cdot \min$ and $177.2 \pm 1.0 \mathrm{~b} \cdot \mathrm{min}$, respectively. These data suggest that high school students participating in surf PE attained HRs and durations that are consistent with recommendations for cardiovascular fitness. Overall, few researchers have examined the effects of surf programs on children with disabilities. Nonetheless, due to previous research findings, surfing is being used, as the focus of physical activity intervention due to its numerous health and therapeutic benefits.

The purpose of the present study was to examine the physiological effects of a surf therapy program on children with disabilities and compare surfing with structured pool play. Surfing programs for children with disabilities are gaining popularity, even though the benefits of these interventions have not been formally studied. This study provides a preliminary exploration of the benefits of ocean surfing in children with disabilities by assessing physiological improvements from the beginning to the end of the surf program. The following research questions were addressed:

RQ1. To what extent do children with disabilities improve their physical fitness upon completion of an 8-week surf program intervention? 
RQ2. To what extent do children with disabilities who participate in a surfing intervention differ in physiological measures from their counterparts who participate in an unstructured or open-ended pool play program?

\section{Methods}

\section{Participants}

This study was approved by the Institutional Review Board at the University of Rhode Island on March 22, 2012 and was renewed each year. The participants were recruited from the University of Rhode Island Adapted Physical Education class, Special Olympics Rhode Island, and the local community. There was a wide range of children with disabilities recruited including: intellectual and learning disabilities, down syndrome, several autism spectrum disorders, microcephaly, global developmental delays, dandy-walker syndrome, heart defects, and hypothyroidism. Individuals interested in participating in the study were required to meet the inclusion criteria of being between 5 and 18 years, diagnosed with a developmental, sensory, and/or physical disability, categorized by disability levels as mild to severe by a parent and/or guardian report, cleared by a medical doctor, have an informed consent signed by their parent/guardian, and an assent form signed by the participant. The categories of disability levels were based on a modified version of the DSM-V to provide a more specific fit to the participants in the study by considering intellectual, emotional, physical and sensory aspects of each individual's disability . Experts divide the types of cognitive impairment into four categories: mild intellectual disability, moderate intellectual disability, severe intellectual disability, and profound intellectual disability ${ }^{23}$. The current study utilized five categories: mild, mild/moderate, moderate, moderate/severe and severe/profound and as recommended by the DSM V, participants were placed in a category based on the type and amount of support needed during 
the intervention. All participants in the programs were comfortable in the water. Knowing how to swim was not mandatory, the children had the option of wearing a life jacket. Attendance was taken at each session .To be included in the study, participants needed to have attended at least thirteen of the sixteen conducted sessions. Data were collected over 6 years $(2012-2017)$. Each year, 15 to 50 children participated in the program with a total of 209 participants over 6 years. Most of the children (77\%) participated in the program for multiple years (17\% for 2 years, $16 \%$ for 3 years, 13\% for 4 years, 7\% for 5 years and 23\% for all 6 years). Adding children who participated in multiple years presents statistical problems as it violates the independence assumption. Instead, we decided to select children who participated in 2017 first and then expanded the subject pool to include children who did not participate in 2017 but participated in earlier years. That way, each participant contributed only one year of data and the most recent year that they participated was included in the statistical analysis. Although data were collected for 6 years, this is not a longitudinal study that followed participants over multiple years. Six years of study data were used in order to have a larger sample size and greater statistical power, especially for participants in the unstructured pool group.

The final statistical sample included 91 participants, 71 participated in the surfing intervention and 20 participated in the unstructured pool play. The children engaged in unstructured free play with typical pool equipment and toys. We used self-selection to allow the participants to choose the activity (pool play or surfing) that they preferred. The decision as to which program the children participated in was entirely up to the parents and participants. The researchers found that some children did not enjoy the beach or ocean, the water was too cold, they did not like sand or waves and preferred the warmth and calm water of the pool. 
To see the demographic differences between these two groups, we employed Fisher's exact test of independence. This method provides a more accurate estimate than chi-square tests when each cell has a small $\mathrm{N}(\text { less than } 5)^{24}$. There were no significant differences observed in the surfing and unstructured pool groups based on gender (Fisher's exact test=1.64, $\mathrm{p}=.26$ ), disability levels (Fisher's exact test $=15.092, \mathrm{p}=0.206$ ), and year (Fisher's exact test $=8.74, \mathrm{p}=$. 08). We also employed Independent sample Mann-Whitney U-tests for age, height and weight, and nonparametric procedures when the distribution was non-normal. There were no significant differences between the two groups in their average height $(U=629, p=.44)$, weight $(U=592.5$, $\mathrm{p}=.26)$ and age $(\mathrm{U}=571, \mathrm{p}=.18)$. That is, participants in the surfing group were comparable to participants in the unstructured pool group in their gender ratio, severity of disabilities (mild to profound), year of participation (2012 - 2017), mean age, mean height and weight. A detailed description of the demographic characteristics of the participants is presented in Table 1 and Table 2.

\section{Design}

This was a research study with a causal-comparative research design that utilized pre and post fitness testing measurements (variables) in order to assess these interventions. Participants self-selected to either the surf or pool group. Random assignment to each treatment, a hallmark of experimental research, was not ethically plausible in this study. Moreover, this study did not include a control group with no exercise at all.. This design was chosen because the researchers noted the lack of opportunities for physical activity and recreation activities in this particular region in the United States. Several families depend on community program offerings from the university throughout the year to ensure healthy lifestyles and habits for their children. 
The effects of the surf therapy on selected physical fitness measures were compared to an unstructured pool play experience. The fitness measures selected were from the Brockport Physical Fitness Test Manual ${ }^{25,26}$. Those that were selected provided a measurement of cardiorespiratory endurance, flexibility, muscular strength, and muscle endurance. For participants in the surf group, we also examined body composition $(\%$ fat mass and fat free mass [FFM]) and bone mineral density.

\section{Measurements}

Multiple dependent variables of fitness were used for this study including: pushups (as a measure of upper body strength), curl-up (a measure of core body strength), 20m Pacer (a measure of aerobic capacity) and back saver sit and reach (a measure of lower body flexibility). Cronbach's alpha shows all measures are reliable ${ }^{2,2,}$ sit and reach $(\alpha>0.95), 20 \mathrm{~m}$ pacer $(\alpha=$ 0.97), pushup ( $\alpha=0.83)$ and curlup $(\alpha=0.82)$. The measures used also have strong content and criterion related validity ${ }^{25,29}$. A goal of the BPFT is to develop an educational component to enhance the development of health-related fitness in youngsters with disability ${ }^{26}$. The populations in this project targeted including youth with intellectual disability, spinal cord injury, cerebral palsy, blindness, congenital anomaly or amputation. This assessment also provides a process that can be used to assess the physical fitness of youngsters with other disabilities. This assessment was tested on thousands of young people with and without disabilities. Classification for children with cerebral palsy was in the ranges of C5-C8 classification system. All participants including those in the moderate and severe categories, ambulated independently and no one was in a wheelchair. The BPFT is valid and reliable for this population ${ }^{26}$. Physical assistance was offered to children with severe disabilities in order to complete the assessments to the best of their abilities. Scores were only counted if the children participated in the tasks independently. 
FFM and bone mineral density were measured with dual energy X-Ray absorptiometry (DEXA), one of the most accurate and well-established methods for direct body composition assessment in healthy children ${ }^{30}$ as well as bone mineral density assessment in children with autism spectrum disorders ${ }^{31}$.

\section{Procedures}

Each surfing participant was paired with an adult instructor for one-on-one surfing instruction. These adult surf instructors were provided with training ${ }^{14}$ on: program goals, surfing as well as teaching skills, and the optimal learning style of each child in order to encourage the maximum progression and participation. The surf instruction consisted of a one-hour session, twice a week, for eight weeks; the children practiced surfing skills during these sessions. Each child was encouraged to progress ${ }^{14}$ from: 1) paddling, 2) balancing on a surfboard while sitting, laying, kneeling or standing, 3) catching a wave and riding it into shore in the prone, sitting, kneeling, or standing positions, and 4) paddling back out through the wave unassisted. The skills ${ }^{14}$ were first practiced in a large group, then each child and their surf instructor would practice their skills one-on-one beginning on land, and then in the ocean. The progression through the skills was based on each child's individual learning pace and the goals set by the surf instructors. Wetsuits were designed and provided to all participants ${ }^{14,32}$. The researchers found that using standard wetsuits for the children was difficult due to the size or shape of the children's bodies. Several of the participant's had an overweight and/or obese BMI, making the standard wetsuits entirely too long. The owner of the surf shop where we rented the equipment (wetsuits and surfboards) quickly realized this issue. In addition, wetsuits can be difficult to put on and take off because it typically involves squeezing the child's body through the neck opening or a small space. The owner took measurements of our participants in the program and 
worked with a wetsuit company to insert zippers on the legs, sleeves, front and back of the wetsuits for a minimal additional cost. This re-designed wetsuit fit the participants perfectly and not only accommodated atypical body types, but also aided in the ease of putting on and removing wetsuits after each session.

The children in the pool program had toys, such as noodles, beach balls, and watering cans to use in one hour of unstructured play. They were supervised for safety only and were not provided with formal instruction or swimming skills development. A practice day was used to familiarize the children with the fitness testing procedures. All procedures outlined in the Brockport Physical Fitness testing manual ${ }^{26}$ were employed.

\section{Statistical Analysis}

This study employs multiple dependent variables of physical fitness: pushups, curl-up, $20 \mathrm{~m}$ Pacer and back saver sit and reach, which were measured twice before and after participating in the program. We also have limited body composition data on $\%$ fat mass, fat free mass and bone mineral density. First, we checked the normality assumption on those dependent variables. All variables, except sit and reach were not normally distributed, calling for nonparametric statistics to be used. For the first research question on improvements of physical fitness upon completion of an 8-week surf program, we employed Wilcoxon signed ranks test for paired samples. This is a nonparametric alternative to the paired samples t-test when the population cannot be assumed to be normally distributed ${ }^{33}$. Analyses were done separately for surfing and unstructured pool program. For research question 2 that addressed differences between surf and pool programs, we used the Mann-Whitney $\mathrm{U}$ test, which is a nonparametric alternative to the independent samples t-test. It is nearly as efficient as the t-test on normal distributions ${ }^{33}$. All analyses were done with IBM SPSS Version 25. 


\section{Results}

Wilcoxon signed ranks tests show significant differences between pre- and post-measures with medium to large effect size for both groups (Table 3). For the surfing group, there were significant differences between pre- and post-measures for all dependent variables: W $($ Wilcoxon test statistic $)=1484.0, \mathrm{Z}($ standardized test statistic $)=3.877, \mathrm{p}<.001, \mathrm{r}($ effect size $=0.477$ for curl-up, $\mathrm{W}=1601.5, \mathrm{Z}=3.816, \mathrm{p}<.001, \mathrm{r}=0.463$ for push-up, $\mathrm{W}=1532.0, \mathrm{Z}=4.221$, $\mathrm{p}<.001, \mathrm{r}=0.524$ for $20 \mathrm{~m}$ pacer run, $\mathrm{W}=1220.5, \mathrm{Z}=3.501, \mathrm{p}<.001, \mathrm{r}=0.434$ for sit and reach right, and $\mathrm{W}=1220.5, \mathrm{Z}=2.544, \mathrm{p}<.05, \mathrm{r}=0.316$ for sit and reach - left. That is, participants in the surfing group made significant improvements from pre- to post-intervention in core body strengths (curl-up), muscle endurance (isometric push-ups in seconds), flexibility (sit and reach) and aerobic functioning (20-m PACER laps). These differences had moderate to large effects according to Cohen's (1988) classification of effect size ${ }^{34}$ which is 0.1 as small effect, 0.3 as moderate effect and 0.5 and above as large effect.

We also examined the differences between pre- and post- measures of body composition using DEXA (Table 3). There were significant changes with very large effect size in total $\%$ fat $(\mathrm{W}=0.00, \mathrm{Z}=-2.366, \mathrm{p}<.01, \mathrm{r}=.789)$, Fat Free Mass $(\mathrm{W}=44.00, \mathrm{Z}=2.547, \mathrm{p}<0.01, \mathrm{r}=0.849)$ and bone mineral density $(\mathrm{W}=45.00, \mathrm{Z}=2.675, \mathrm{p}<0.05, \mathrm{r}=0.892)$ before and after participation in the surfing program $(\mathrm{N}=9)$. We acknowledge the limited generalizability of this small sample, however, these data provide supplementary evidence to support the findings of physiological improvements in the surfing group.

As for the unstructured pool group, we employed exact significance test as there were less than 25 participants. The main characteristic of exact methods is that statistical tests are based on exact probability statements that are valid for any sample size. Exact statistical methods 
help avoid some of the unreasonable assumptions of traditional statistical methods ${ }^{35}$. There were significant differences between pre- and post-measures on all variables: $\mathrm{W}=170.0, \mathrm{Z}=2.495$, $\mathrm{p}<.05, \mathrm{r}=0.558$ for curl-up, $\mathrm{W}=170.0, \mathrm{Z}=3.021, \mathrm{p}<.01, \mathrm{r}=0.676$ for push-up, $\mathrm{W}=190.0, \mathrm{Z}=3.843$, $\mathrm{p}<.001, \mathrm{r}=0.859$ for $20 \mathrm{~m}$ pacer run, $\mathrm{W}=150.0, \mathrm{Z}=2.835, \mathrm{p}<.01, \mathrm{r}=0.668$ for sit and reach - right, and $\mathrm{W}=141.5, \mathrm{Z}=2.465, \mathrm{p}<.05, \mathrm{r}=0.581$ for sit and reach - left. It appears that participants in both groups made significant improvement after participating in the 8-week programs (Table 3). Mann-Whitney U tests were used to examine the differences between the surf and pool groups on various fitness measures (Table 4). This test is used to determine whether two independent samples were selected from populations having the same distribution when the normality assumption is not met. There were no significant differences between the surfing and the pool groups on any of the fitness measures.

Our analyses indicate that both the surfing group and the unstructured pool-play group made significant improvements in physical fitness after an 8-week program. In addition, the surf group showed significant changes in body composition and bone-mineral density over the 8week surfing intervention.

\section{Discussion}

The purpose of this study was to explore the physiological effectiveness of a surfing intervention for children with disabilities, and to fill in some of the gaps in the literature. We compared pre- and post-measures for both the surfing and unstructured pool-play groups individually and against each other. Our hypotheses were only partially supported. These results indicated that the surfing participants improved in the various components of physical fitness as well as in measures of body composition. There were significant improvements in the surf group in: upper-body strength, core strength, lower body flexibility and cardiorespiratory endurance, 
bone mineral density, fat free mass as well as a significant reduction in total percent body fat. However these findings need to be interpreted with caution as participants in the pool group also showed significant improvements in their physical fitness. This may be explained by an examination of Metabolic Equivalents [METs] used during surfing and unstructured pool play. METs are a well-established method of determining intensity ${ }^{36}$ (low, moderate, vigorous) of physical activity by quantifying how much energy is expended during the activity. In adults surfing $^{37}$ is estimated to expend between 3.0 - 5.0 METs (moderate intensity) and general swimming ${ }^{37}$ is estimated to expend between 3.5 - 6.0 METs (moderate intensity), indicating that both are comparable moderate intensity activities in adults. In children swimming at a selfselected pace ${ }^{38}$ is estimated to expend between 8.6 - 9.5 METs (vigorous intensity) for children between the ages of 6-18 years. This may be why both the pool group and the surf group showed comparable improvements in physical fitness measures.

The improvements that we report in physical fitness in the surfing group suggest that this is another activity that can be added to the repertoire of effective adapted aquatic programs. These improvements (surf group) could be attributed to carrying the surfboard, use of the core and stabilizer muscles to balance on the surfboard, and the repetitive arm motion needed to paddle out through the break and to catch a wave. We found a substantial increase in core body muscle endurance as assessed with the curl-up test in the surfing but not the unstructured pool playgroup. These improvements are likely due to moving from the prone to the push-up position to the upright stance position (also known as the "pop up" in surfing). Past research indicates that one of the most important benefits of surfing was the increase in cardiorespiratory endurance and our results are consistent with the literature. Past research also indicates that children with disabilities have low levels of cardiorespiratory endurance when compared with their abled- 
bodied peers ${ }^{4,9,39}$. Surfing is a highly aerobic activity ${ }^{21}$ that brings about significant improvements in cardiorespiratory endurance ${ }^{7,8}$ after a 14 -week aquatic aerobic exercise intervention. The significant improvements in body composition as evidenced by reductions in total $\%$ body fat and increases in fat free mass and bone mineral density indicates that surf therapy can be considered a valid approach to reduce the prevalence of childhood obesity.

This study compared the physical fitness of children in a surfing program to children in an unstructured aquatic program. One of the limitations of this study is that this study does not compare the surfing program with a sedentary control group. In the future, it would be beneficial to do a randomized experimental study with a sedentary control group in order to better understand the effects of surfing as an adapted program for children with disabilities. In addition, the sample used in this study was too small to capture the significant differences between surfing and pool playgroups. Power analysis using $\mathrm{G}^{*}$ Power $^{40}$ indicates the total size of 91 is not large enough for a between-group comparison. Actual effect size for between-group differences was found to be less than 0.15 (Table 4). In order to detect such a small effect for Mann-Whitney test, the desired sample size is over 2000 with $\alpha=.05$ and power $=.80$. It appears that the small between-group differences are partly due to the fact that the pool playgroup may not have functioned as the optional comparison group as participants were not entirely sedentary and participated in some vigorous intensity ${ }^{37}$ aquatic activities. To determine larger between-group differences ( $\mathrm{r}=0.5)$, a sample of 190 participants ( 150 in the surf therapy group, 40 in the pool group) is needed with a power $=0.8$ and $\alpha=.05$. The results for within-group analysis are promising as it shows significant improvements in upper-body strength, core strength, flexibility, cardiorespiratory endurance and body composition after engaging in the 8-week program for both the surfing and pool therapy groups. The sample used in this study is powerful enough to 
detect within group differences for pre- and post-measures using Wilcoxon signed rank tests. The desired sample to detect large within-group differences in performance was found to be 35 $(r=0.5)$ and the desired sample to detect medium within-group differences in performance was found to be $94(\mathrm{r}=0.3)$, with power $=0.8$ and $\alpha=.05$. Finally, lack of a follow-up measure is also a limitation of the study. Future studies in this area would benefit from a follow-up measure.

Anecdotally, our researchers, surf instructors, and parents reported numerous positive outcomes. They observed increased self-confidence, gains in social development, and decreased anxiety in the children. Some of these improvements included increased verbalization, excitement and motivation about physical activity, and improvements in surfing skills. Several outcomes of the program were also reported to carry over into other areas of the participants' lives including: increased participation and improved performance in other physical activities such as adapted physical education classes, the Special Olympics and Unified Sports. This aligns with previous findings on parent and caregiver reported benefits of surf therapy. It is recommended that future research examine these reported improvements formally ${ }^{17}$.

\section{Conclusions}

The results of this study indicate that a surfing intervention is feasible, as well as beneficial to the physical fitness of children with disabilities. Based on the fitness testing and feedback from participants and parents, it appears that a surfing intervention can be effective in improving the lives of children with disabilities. We had no untoward events occur and therefore health and physical education departments might consider incorporating surfing into their curriculum as a way to provide variety. 
Grant Funding: Grant funding to support the program was obtained from the John Fogarty Foundation, Doug Flutie Foundation, Bailey's Team Foundation, and from the Brayden Carr Foundation and a local surf shop, Peter Pan Surf Academy, donated 50\% of the cost of the equipment rentals. The role of these sponsors was to provide support for free community programming for children with disabilities and their families. 


\section{References}

1. Ogden, C.L. \&Carroll, M.D. \& Kit, B.K. \& Flegal, K.M. (2014). Prevalence of childhood and adult obesity in the United States, 2011-2012. The Journal of the American Medical Association, 311(8), 806-814.

2. Ogden, C.L. \& Carroll, M.D. \& Fryar, C.D. \& Flegal, K.M. (2015). Prevalence of obesity among adults and youth: United States, 2011- 2014. NCHS data brief, No. 219.

Hyattsville, MD: National Center for Health Statistics.

3. Center for Disease Control and Prevention. (2016). How much physical activity do children need? Retrieved March 6, 2017 from:

http://www.cdc.gov/physicalactivity/basics/children/index.htm.

4. Murphy, N. A. \& Carbone, P. S. \& Council on Children with Disabilities. (2008).

Promoting the participation of children with disabilities in sports, recreation, and physical activities. Pediatrics, 121, 1057-1061.

5. Rimmer, J.H. \& Yamaki, K. \& Lowry, B.M. \& Wang, E., \& Vogel, L.C. (2010). Obesity and obesity related secondary conditions in adolescents with intellectual/developmental disabilities, Journal of Intellectual Disability Research, 54(9), 787-794.

6. United States Department of Health and Human Services. President's Council on Sports, Fitness and Nutrition. Physical Activity Facts. Retrieved on: September 24, 2018 at https://www.hhs.gov/fitness/be-active/physical-activity-initiative/index.html.

7. Fragala-Pinkham, M. \& Haley, S. M., \& O’Neil, M.E. (2008). Group aquatic aerobic exercise for children with disabilities. Developmental Medicine \& Child Neurology, $50(11), 822-827$. 
8. Fragala-Pinkham M. \& O’Neil M.E. \& Haley S.M. (2010) Summative evaluation of a pilot aquatic exercise program for children with disabilities. Disability and Health Journal, 3(3):162-170.

9. Hayden, M. (1998). Mortality among people with mental retardation living in the United States: Research review and policy application. Mental Retardation, 36, 345-359.

10. Okagaki, L. \&Diamond, K.E. \& Kontos, S.J., \& Hestenes, L.L. (1998). Correlates of young children's interactions with classmates with disabilities. Early Childhood Research Quarterly, 13, 67-86.

11. Rimmer, J.H. \& Riley, B. \& Wang, E. \& Rauworth, A., \& Jurkowski, J. (2004). Physical activity participation among persons with disabilities. American Journal of Preventative Medicine, 26(5), 419-425.

12. Bravo M.M. \& Cummins K. \& Nessler J.A. \& Newcomer S.C. (2016). Heart rate responses of high school students participating in surfing physical education. The Journal of Strength and Conditioning Research, 30(6), 1721-1726.

13. Toporek, B. (2011). Surfing to become official school sport in Hawaii. Retrieved March 1,2017 from http://blogs.edweek.org/edweek/schooled_in_sports/2011/10/surfing_to become_official school_sport in hawaii.html.

14. Clapham, E.D., Armitano, C.N., Lamont, L.S, \& Audette, J.G. (2014). The Ocean as a Unique Therapeutic Environment: Developing a Surfing Program. Journal of Physical Education Recreation and Dance, 85(4), 8-14.

15. Lamont, L.S., Armitano, C.N. \& Clapham, E.D. (2014). Ocean surfing as a novel physiotherapy environment: a commentary. Journal of Novel Physiotherapies, 4, 2-4. 
16. Armitano, C.N., Clapham, E.D., Lamont, L.S. (2015). Benefits of Surfing for Children with Disabilities: A Pilot Study. PALAESTRA, 29(3), 31-34.

17. Moore, A., Clapham, E.D. \& Deeney, T. (2017). Parents' Perspectives on Surf Therapy for Children with Disabilities. International Journal of Disability, Development and Education. doi: 10.1080/1034912X.2017.1400660

18. Lopes, J.T. (2015). Adapted surfing as a tool to promote inclusion and rising disability awareness in Portugal. Journal of Sport for Development, 3(5), 1-7.

19. Cavanaugh, L. \& Rachmacher, S. \& Rachmacher, J. \& Simmons, R. (2013). Planning and Implementing a Surf Camp for Students with Autism Spectrum Disorder. Palaeastra, 27(1), 17-22.

20. Pittsinger, R. \& Kress, J. \& Crussmeyer, J. (2017). The effect of a single bout of surfing on exercise-induced affect. International Journal of Exercise Science, 10(7), 989-999.

21. Farely, O.R.L. \& Secomb, J.L. \& Raymond, E.R. \& Lundgren, L.E. \& Ferrier, B.K. \& Abbiss, C.R. 7Sheppard, J.M. (2018). Workloads of competitive surfing: work-to relief ratios, surf-break demands, and updated analysis. Journal of Strength and Conditioning Research, 0, 1-10. DOI:10.1519/JSC.0000000000002659

22. Mendez-Villanueva A., \& Bishop, D. (2005). Physiological aspects of surfboard riding performance. Sports Medicine, 35(1), 55-70.

23. American Psychiatric Association. (2013). Diagnostic and statistical manual of mental disorders (5th ed.).

24. Ruxton, G.D., \& M. Neuhäuser. (2010). Good practice in testing for an association in contingency tables. Behavioral Ecology and Sociobiology, 64, 1501-1513. 
25. Plowman, S.,A., \& Corbin, C.B., (1994), Muscular strength, endurance, and flexibility. In J,R, Morrow, H,B, Falls, \& H.W, Kohl (Eds.), The Prudential FITNESSGRAM technical reference manual (pp, 73-99), Dallas, TX: Cooper Institute of Aerobic Research.

26. Winnick, J. \&, Short, F. (2014). The brockport physical fitness test manual: A health related assessment for youngsters with disabilities. 2nd Champaign, IL: Human Kinetics.

27. Short, F. \& Winnick, J. (2005). Conceptual Framework for the Brockport Physical Fitness Test. Adapted Physical Activity Quarterly, 22(4), 323-332.

28. Eichstaedt, C. \& Lavay, B. (1992). Physical activity for individuals with mental retardation. Champaign, IL: Human Kinetics.

29. Patterson, P. \& Wiksten, D.L. \& Ray, L. \& Flanders, C.\& Sanphy, D. (1996). The validity and reliability of the back saver sit and reach test in middle school girls and boys. Research Quarterly for Exercise and Sport, 67, 448-451.

30. Weber, D.R., Leonard, M.B. \& Zemel, B.S. (2012) Body Composition Analysis in the Pediatric Population. Pediatric Endocrinology Review, 10(1): 130-139

31. Ekhlaspour, L., Baskaran, C., Campoverde.K.J., Sokoloff, N.C., Neumeyer, A.M., \& Misra, M. (2016) Bone Density in Adolescents and Young Adults with Autism Spectrum Disorders. Journal of Autism and Developmental Disorders, 46(11)- 3387 3391

32. Lamont, L.S, Panagiotis, P. Armitano, C.N., Clapham, E.D. (2013). Development of a wetsuit for children with Down Syndrome. International Journal of Aquatic Research and Education: 8:98-103.

33. Hollander, M. \&, Wolfe, D. A., \& Chicken, E. (2014). Nonparametric Statistical Methods ( $3^{\text {rd }}$ ed.). New York: John Wiley \& Sons. 
34. Cohen, J. (1988). Statistical power analysis for the behavioral sciences $\left(2^{\text {nd }}\right.$ ed.). Hillsdale, NJ: Lawrence Earlbaum Associates.

35. Weerahandi, S. (1995). Exact Statistical Method for Data Analysis. New York: SpringerVerlag.

36. Haskell, W.L., Lee, I.M., Pate, R.R., Powell, K.E., Blair, S.N., Franklin, B.A., Macera, C.A., Heath, G.W., Thompson, P.D., Bauman, A. (2007) Physical Activity and public health: updated recommendations from the American College of Sports Medicine and the American Heart Association. Medicine and Science in Sports and Exercise, 39(8), 14231434.

37. Ainsworth, B.E., Haskell, W.L., Herrmann, S.D., Meckes, N., Bassett Jr, D.R., TudorLocke, C., Greer, J.L., Vezina, J., Whitt-Glover, M.C., Leon, A.S. (2019) The Compendium of Physical Activities Tracking Guide. Healthy Lifestyles Research Center. College of Nursing \& Health Innovation, Arizona State University. Retrieved from https://sites.google.com/site/compendiumofphysicalactivities/

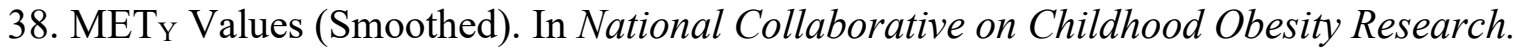
Retrieved July 192019 from https://www.nccor.org/tools-youthcompendium/backgroundand-history/

39. Fernhall, B. \&, Pitetti, K. (2001). Limitations to work capacity in individuals with intellectual disabilities. Clinical Exercise Physiology, 3, 176-185.

40. Faul, F. \& Erdfelder, E. \&Lang, A.-G. \& Buchner, A. (2007). G*Power 3: A flexible statistical power analysis program for the social, behavioral, and biomedical sciences. Behavior Research Methods, 39, 175-191. 
